\title{
Aproximaciones a la subjetividad entre Esta rosa negra y Arte de morir de Óscar Hahn
}

\author{
Approaches to subjectivity between Esta rosa negra \\ and Arte de morir from Óscar Hahn
}

\author{
Alejandra Leal Ladrón de Guevara \\ Universidad Austral de Chile. Puerto Montt, Chile \\ alejandraleal@spm.uach.cl
}

\section{RESUMEN}

En este estudio comparativo se describen las marcas textuales de dos obras poéticas de Óscar Hahn: Esta rosa negra (1961) y Arte de morir (1977) para significar, en un caso, el concepto del exilio y la soledad y, en el otro, la presencia de la subjetividad y solidaridad en un período de la historia de Chile en donde el arte es dominado por la muerte y la enajenación.

Palabras clave: Subjetividad, exilio, historia de Chile, poética de Hahn.

\section{ABSTRACT}

This comparative study describes two poetic works by Óscar Hahn textual markings: Esta rosa negra (1961) y Arte de morir (1977) to mean, in one case, the concept of exile and loneliness and, on the other hand, the presence of subjectivity and solidarity in a period of the history of Chile where art is dominated by the presence of death and alienation.

Keywords: Subjectivity, exile, history of Chile, poetry of Hahn.

Recibido: 16.10.2012. Aceptado: 14.03.2013. 


\section{INTRODUCCIÓN}

T as circunstancias históricas que afectan a la sociedad chilena y directa1 mente a los escritores entre 1960-1970, son las causas generadoras del desarraigo en la escritura del chileno Óscar Hahn. Una explicación acerca de la desconexión de la realidad es enmarcada en el análisis histórico-crítico expuesta por Donoso Pareja (1992), quien señala dos causas para los cambios que experimenta el hombre tras el exilio: “...de nosotros mismos, por un lado, y en nuestra escritura, por otra” (1992: 156); las instancias que alejan la presencia de la subjetividad y del equilibrio humano en la escritura de Hahn. Al respecto, las facultades del hombre para dominar su ser, dirá José Ortega y Gasset, se encuentran en el descubrimiento de la 'subjetividad', en la interioridad del pensamiento; el aspecto determinante que conduce a comprender qué "es la mente, la conciencia, el pensamiento, la subjetividad y el espíritu, el yo" (Ortega y Gasset, 1965: 157). De manera que el hombre de cualquier época, al desconocer ese modo de ser subjetivo y reflexivo, correspondiente al entero dominio de su conciencia y su ser, queda desplazado a un estado anterior.

Desde una perspectiva social, la suma de los actos que presagian el autoritarismo político de la época cuando Óscar Hahn publica su primera obra (1961), revelan los estados de tensión que operan en la sociedad chilena. De acuerdo a ello, un gran número de artistas comunican sus representaciones de la realidad, ciertamente desarraigadas, a través del arte de la poesía. Javier Campos (1987) explica este contenido acorde con la realidad conflictiva y de la transformación crítica de los artistas, ciertamente motivados por una orientación socio-histórica que se testimonia con los documentos recopilados por Soledad Bianchi (1995) en la entrevista a Gonzalo Millán:

Pienso que nuestra infancia y juventud no fue una experiencia agradable; yo, de partida, sentí que la realidad social que me tocaba vivir era negativa, era un mundo hipócrita, autoritario, represivo, y creo que la experiencia de Waldo Rojas, como la de Hahn y la mía, dan cuenta de ello, y esto solamente se acentúa con el Golpe Militar, o sea, al autoritarismo militar que se impone, después del Golpe, nosotros lo sentimos en carne propia (Bianchi, 1995).

De acuerdo a esto, el descontento social experimentado por los artistas de este período se indica como el sentimiento de la minoría apabullada por las circunstancias histórico-políticas. Esto conduce a algunos escritores a 
desarrollar estrategias para distanciarse de los hechos y de sí mismos, conformando procesos donde opera el desarraigo y, en consecuencia, la ausencia de la subjetividad asumida.

No obstante, esto privilegia la representación enunciativa de una escritura carente de subjetividad. De acuerdo a ello, los textos analizados en este trabajo, Esta rosa negra (1996 [1961]) y Arte de morir (2000 [1977]), son los hitos del proceso de enseñanza marcada por el exilio y la soledad que experimenta el autor real Óscar Hahn antes, durante la dictadura y 'el golpe militar' en Chile. Pues, cabe señalar que para la edición de Esta rosa negra en 1961, Óscar Hahn no contaba con más de 21 años, por consiguiente, la construcción de la subjetividad en la enunciación de su discurso no se producirá al azar, más bien se hará por un enfrentamiento y dominio de los personajes ficticios como la muerte en esa realidad agobiante que le tocará vivir.

\section{MARCO REFERENCIAL}

En este marco, a partir de la lectura interpretativa de estos dos textos, se articulan los valores culturales y sociales en el proceso interno y externo que facilitan la significación de la escritura de Hahn entre 1961 y 1977. En este sentido, la parte significativa del texto que permite reconocer al sujeto productor del discurso, siendo un concepto muy controversial (Morín, 1994), en este estudio estará circunscrito a la enunciación, en donde los sujetos del discurso (enunciador - enunciatario), sean éstos reales o imaginados, se alojan en las 'marcas textuales' a través de pronombres, verbos conjugados y figuras del pensamiento; de manera que el discurso implicará a los sujetos: enunciador, enunciatario y al objeto enunciado (Maingueneau, 1976, 2004; Charaudeau, 1992, 2001; Martínez, 1997a, 2005). De acuerdo a ello, Maingueneau plantea que "el sentido de un enunciado se define fuera de todo marco enunciativo, mientras que su significación está referida a las circunstancias de comunicación que hacen de él un discurso" (1976, 2004). En consecuencia, el enunciado se convierte en discurso con una significación específica, adicionando un sentido-consenso entre los hablantes de la lengua que lo representan en una categoría del marco enunciativo. Por lo tanto, puede haber discurso sin representación de la enunciación en cuanto ésta constituye el vehículo para lograr la significación; así se dirá que las 'modalizaciones' están usadas para organizar el discurso, adoptando una posición hacia lo que dice, hacia quién lo expresa, y hacia sí mismo, acciones válidamente presentes en la conciencia del sujeto (Charaudeau, 1992; Flo- 
res, 1991; Cepeda, 2005; Álvarez, 2005; Grau, 2005). Éstas corresponden al conjunto de huellas lingüísticas y enunciativas que desaloja el enunciador en el texto, construyendo la posición del sujeto en el enunciado a través de apreciaciones, opiniones, actitudes, creencias, etc. y que se caracterizan en un continuo del proceso estrechamente vinculadas a los 'actos de habla' en la situación comunicativa (Benveniste, 1997; Austin, 1962; Ducrot y Todorov, 1972; Ducrot, 1986; Maingueneau, 1976; Haverkate, 1994, Searle, 2001; Grau, 2005). Vale destacar que estas modalizaciones señalarán al enunciador en su intención de aproximarse o de distanciarse del objeto de atención perturbadora; de tal manera que los discursos más modalizados resultan más subjetivos, opuestos a los menos modalizados que son más objetivos (Grau, 2005: 85).

En este trabajo, el tiempo será tratado bajo dos parámetros, el primero es propiamente lingüístico, por cuanto alude a estados de consonancia con la enunciación y la historia del presente verbal en coexistencia con el acto de habla de pasado o anterioridad y de futuro o posterioridad (Roa, 1989; Di Tullio, 2005). El segundo, guarda relación con la categorización de la existencia y la acción; ambas actualizadas en la enunciación del discurso. Pues, cabe destacar que estos principios mantienen un valor semiótico del hecho (Eco, 1995), lo que permite establecer la relación con el momento de la realidad donde el enunciador germina intelectualmente en una literatura apasionada (eufórica), plena de imágenes liberadoras.

Se debe destacar que al hablar de subjetividad no se niega la existencia de lo objetivo. Pues, la expresión subjetiva se entenderá como aquella "que tiene por base percepciones, vivencias y reflexiones individuales" (Vodicka y Belic, 1972: 54). Esto permitirá observar el hecho histórico-objeto del proceso hacia la subjetividad (identidad) de Óscar Hahn: la marcha al exilio como un nuevo éxodo en donde la realidad opera por la censura y los patrones de la pérdida, la nostalgia y el desarraigo que libera tensiones y, con ello, 'demonios' destructivos. Aludiendo a la realidad que experimentan los exiliados en el extranjero, Donoso Pareja (1992) lo llamará integración de lo objetivo dentro de lo subjetivo, es decir, la vivencia de la voz colectiva en la expresión de la voz del individuo.

\section{INTERACCIÓN DEL DIÁLOGO INTERTEXTUAL}

Los indicios de la primera representación trialógica del discurso (enunciador - enunciatario - referente enunciado) se evidencia en los marcadores del 'yo' 
- 'tú' que apuntan al referente evocado en la muerte fundacional del primer discurso, Esta rosa negra (ERN). Así también, la segunda representación, Arte de morir (ADM) se haya re-semantizada entre los enunciadores yo-tú como, así, aludiendo al referente representado en la muerte.

\subsection{Desarrollo de los modos enunciativos y los tiempos verbales}

De acuerdo a esto, el poema inaugural de ERN "Soy una piedra lanzada de canto", desde ahora fundacional, recrea al hablante enunciador mediatizado por dos oraciones interrogativas dubitativas a través del verbo modal del presente indicativo "soy", revelando cómo el sujeto enunciador interviene en la acción: "¿Soy el lanzado como piedra / por la mano de Dios, / en el agua de la existencia? ¿ ¿Soy el que en ondas circulares / irá creciendo / hasta desbordarse en el vacío letal?" (1996: 21).

Así pues, las oraciones interrogativas directas no expresan ni afirmación ni negación, aunque inquieren o preguntan sobre la realidad de un hecho que, en este caso, remite al sujeto tácito "yo" (Roa, 1989). Estas dos oraciones interrogativas son dubitativas, en la medida que el hablante enunciador "yo" se pregunta algo, expresando incertidumbre acerca de ese algo existencial; el verdadero tránsito por donde la piedra es enviada por la mano de Dios. De igual modo, el uso de la mayúscula nos permite advertir que el enunciador reconoce un Dios único y omnipresente para estas acciones.

Luego, el uso de los adverbios de duda (acaso, tal vez, quizá), se estructuran implícitamente de la siguiente forma: "soy (acaso) el lanzado...". De manera que el hablante enunciador de este discurso inaugural es "como" una piedra, pues ni siquiera es una real piedra lanzada. Entonces, la duda existencial es un "yo" indefinido por una figura comparativa: una piedra lanzada por la mano de Dios que, de manera concluyente, se significa en el nivel sintáctico de la siguiente manera: "¿(Yo) Soy (acaso) el lanzado como piedra por la mano de Dios".

De acuerdo a la asunción de la subjetividad, cuyo proceso se inicia con la construcción de la identidad en el exilio existencial, es semantizada en los siguientes versos: "¿Soy el lanzado como piedra / por la mano de Dios, / en el agua de la existencia?” (1996: 21), en donde la carga emotiva de verse "lanzado como piedra... en hondas circulares" permite inferir una nueva estructura que revela la imagen plástica de ir rebotando sobre la superficie del agua, en el agua de la existencia como, además, en el abandonado de Dios.

Así, pues, conectando el discurso de este texto y de aquel que se lee sig- 
nificando los momentos previos al 'golpe militar', se visualiza cierto carácter premonitorio del conflicto social y del tránsito del poeta hacia el exilio, ocasionado por la circunstancia de "exiliarse" hacia una escritura desarraigada.

De modo que esta valoración obedece a patrones testimoniales donde se señala la negatividad de la vida guiada por la hipocresía y la opresión, entre otros sentimientos adversos (Bianchi, 1995); en cuyo conjunto se significa una retrospectiva que ha servido a los críticos para reconocer las intuiciones de lo que venía en camino: la dictadura. De acuerdo a ello, la instrumentalización del lenguaje por el que se realiza el acto de la enunciación aún no cristaliza la subjetivación del enunciador, aunque se infiere por el significado. Por consiguiente, en la segunda oración interrogativa este sujeto se representa a sí mismo de modo profético en el abandono, al decir: "¿Soy el que en ondas circulares / irá creciendo / hasta desbordarse en el vacío letal?" (1996: 21).

\subsection{Presencia de la temporalidad y la localidad}

Las modalidades de la enunciación representadas en los adverbios de tiempo 'ahora' y de lugar, tales como 'alli' y 'aquí', aluden al comportamiento ubicuo de la enunciación y la acción témporo-espacial: "Heme aquí".

A partir de esto, se reconoce la secuencia de tres signos gramaticales, siendo los dos primeros correspondientes al enclítico (Roa, 1989); de los cuales, el primero, pertenece al tiempo presente del verbo haber ' $h e$ ', el segundo, el pronombre ' $m e$ ' $y$, el tercero, el adverbio de lugar 'aquí. En suma, los tres concuerdan en un acto continuo que se mantendrá en el proceso de subjetivación o asunción del yo explícito hasta Arte de morir, a la manera de ir: "creando la inmensidad de Dios / imagen y semejanza de la muerte" (1996: 22).

En resumen, se señala que el hablante representa el curso del abandono existencial de Dios a través de la imagen siniestra de la muerte.

\subsection{Pronominalización y autotextualidad}

La autotextualidad, entendida como la variante de la intertextualidad o intertextualidad autártica (Dallenbach, 1976), se refleja en el siguiente poema titulado: "Reencarnación de los carniceros": "Y vi que los carniceros, al tercer día, / al tercer día de la tercera noche, / comenzaban a florecer en los cementerios / como brumosos lirios o como líquenes" (1996: 30).

Nuevamente, el pronombre de primera persona "yo" está ausente e im- 
plícito en la forma verbal. Esta vez el modo indicativo se presenta en el tiempo pretérito indefinido ' $v i$ ', acoplado a un acto continuo de los tiempos del pretérito imperfecto (comenzaban, volaban, jugaban, reencarnaban, vegetaban), los que aluden a los sujetos de la acción, "los carniceros". Del mismo modo, la referencialidad subordinada al acto enunciativo se explicita en la forma verbal de la primera persona: ' $v i$ '. En este sentido, la marca indicial de la oración subordinada sustantiva: "que los carniceros...comenzaban... volaban... etc...", permite inferir el acto profético subordinado al Apocalipsis de San Juan. Aunque ahora, re-semantizado en el contexto y las circunstancias personales y sociales previos a la señalada dictadura militar.

A partir del verso que declara "Y vi que..." se completa la visión del estado de los carniceros junto al acto actualizado de "se están matando", complementado por la imagen "entre ellos". De manera que los referentes de la enunciación remiten a un hecho situado, real, continuo e infinito.

Además, en los últimos versos del penúltimo poema: "Danza de la muerte" se lee: “...mezclándome a los vahos que se fugan / de mi greda sangrante; / tapiándome la muerte / con todos sus cementos, / mi voz se evade en ti, / mi agua se va de ti, / mi alma se va de ti" (1996: 38). En este texto, la pronominalización del 'yo' enunciativo se presenta en la marca lingüística indirecta 'me', fraccionada en las muertes que el hablante deberá cursar. Por esto, los signos relevantes son: la imagen evadida en la amada ' $t i$ ', la sexualidad en el 'agua' y, también, la pérdida de la primera existencia reflejada en el 'alma'.

Resumiendo lo anterior, este primer discurso fundacional exhibe la génesis de la escritura de Óscar Hahn en las marcas gramaticales actualizadas en el acto de la enunciación, trazando la imagen del ' $y o$ '; las cuales son un símil de la construcción de la subjetividad y del carácter profético del libro de San Juan apóstol. Del mismo modo, la realidad chilena pre y postgolpe militar, según consta en "La transformación de la muerte en la poesía de Óscar Hahn" (Campos, 1987), alude a las especificaciones del tratamiento de la muerte circunscrita a la poesía chilena y latinoamericana contemporánea. Esto último reseña aquella muerte ligada al trabajo humano y al movimiento de la historia, es decir, todas las muertes cargadas de soledad; desgarradoras e individualistas, como dialéctica e histórica: "Hahn recogerá la humanista y vital imagen de esta última" (Campos, 1987). En definitiva, la literatura del período se explicita en representaciones de un fuerte carácter subjetivo evidenciado en la multiplicidad de los hablantes, "sujetos enajenados y dislocados", al parecer, un producto de aquella realidad histórica (Galindo, 2002: 98). 
Complementariamente, se infiere que Hahn es un poeta lúcido de la realidad y de la metáfora de los tiempos, testimonial y eufórico, cargado de "la tensión que se produce entre censura y autocensura buscando el lugar del sujeto" (Galindo, 2002: 98), como de sí mismo en el Cosmos. Debido a esto, el valor pasional obedece al carácter histórico de lo vivido por Hahn hasta la edición de ERN, de cuya selección de textos se editan aquellos que fueron escritos hasta 1959 a los solo 21 años del poeta. Posteriormente, estas vivencias lo llevarán como un trasplantado al exilio, sumándose la problemática vital de la soledad. Por ello dirá: "Hoy me pesqué una soledad tremenda / Y los caballos de la muerte cruzan" (Hahn, 1996: 38). Por tanto, el discurso fundacional es el hilo conector hasta la subjetividad del poeta. En la primera (que es la última) de sus muertes: "Elevación de la amada", cargado de pasión eufórica, expondrá: "¿Quién eres tú, quién eres tú, oh incandescida / por los musgos del tiempo, / para que de ti yo tenga muertes!” (Hahn, 1996: 44).

\subsection{Los modos enunciativos y los tiempos verbales en Arte de morir}

Este segundo discurso 'trialógico' de ADM se construye situacionalmente a partir del primer texto con la presencia de la muerte como la protagonista del carnaval mortuorio. Allí, pues, en el evento de danzar están invitados desde los simples "lacayos" hasta los magnánimos "reyes", quienes lanzarán bufidos y exhalarán gritos en el curso del ritual: "lacayos y reyes lanzando bufidos / tomados del brazo ya danzan unidos" (2000: 5).

Por tanto, para que se efectúe este acto iniciático: "un ropavejero será tu pareja" / "tendrás que entregarle tu carne más vieja / y en puro esqueleto dar saltos tullidos" (2000: 5). Aunque todavía cabe preguntarse cómo es el proceso de construcción de la representación del 'yo' en la enunciación; cuáles son los signos del yo poético y las marcas de la subjetividad e identidad del poeta. Esto se constata en el segundo texto en la medida que se dice: "La muerte está sentada a los pies de mi cama" (2000: 7), donde los marcadores pronominales son la antesala al primer enfrentamiento directo; la ocasión en que la realidad se sujeta a la representación de las imágenes discursivas. De modo que este poema funciona conectado al discurso inaugural de la misma serie, contextualizado espacial y temporalmente en una habitación y en la noche: "mi cama está deshecha..." / "...esta noche es la fecha" (2000: 7).

Recapitulando, este poema fraccionado proporciona una relación dialógica entre la muerte y el hablante, donde este último asume un enfrenta- 
miento discursivo directo, mediatizado por la oración gramatical subordinada sustantiva, la cual se agiliza con el efecto de una 'narración': "la muerte dice ahora que..." / "le suplico que..." / "se acomoda y replica que..." / "le contesto que..." (2000: 7). Así también, el pronombre en primera persona 'yo' aún está ausente, aunque expresado por la forma modal de las desinencias verbales: "suplico, contesto, trato, callo...", como además, el diálogo indirecto con el pronombre ' $l e$ ' indica hacia quien va dirigido el mencionado texto: "ella, esta muerte, la muerte". En consecuencia, el primer encuentro con la pronominalización de la primera persona 'yo' remite a una cronología en donde la muerte permanece a los pies de la cama: "yo trato de espantarla..." (2000: 7).

En resumen de lo anterior, el texto "La muerte está sentada a los pies de mi cama" (2000: 7) es el primer encuentro dialógico del enunciador con la muerte, abriendo el camino a la subjetividad en aquellos encuentros figurativos con la muerte.

Así es como en el texto "Para darle cuerda a la muerte" (2000: 32) el hablante señala otro encuentro eventual, dando el curso a la muerte sensoria de la sexualidad, en donde el yo enunciativo está marcado lingüísticamente en el acto de decir: "Cuando se me alborotan los espermios, / qué veo, qué veo, digo yo: / veo a mis pescaditos navegar por los úteros, / enamorados de cuanto óvulo cae" (2000: 32).

La muerte en el recuerdo del texto "Letanía para un poeta difunto" (2000: 44) es otro momento discursivo conducente al yo enunciativo. Es un poema de ERN (1961) reformulado en ADM, el cual conduce a inferir que la autotextualidad no es figurativa, más bien concreta en la construcción del yo. Pues, son idénticos en los primeros versos: "Ahora o en un primero de noviembre / me recuerdo de tu infinita muerte" (2000: 44).

No obstante, un momento discursivo de ADM en el poema "La muerte tiene un diente de oro" se señala como un pasaje definitivo y estructurador de la dominación del yo del hablante; la instancia representativa del discurso fundacional del 'yo' poético: "Yo tuteo a la muerte. / Hola, flaca, le digo. ¿Cómo estái?” (2000: 45). Esto último, en la medida que la pronominalización de la primera persona singular 'yo' también relaciona las formas verbales "tuteo, digo" del tiempo presente indicativo. Asimismo, es un indicador de la dominancia en los encuentros con la muerte referencial, aunque no absoluta, ya que el yo enunciativo se refiere a sí mismo inmaduro ante una muerte de vasta experiencia: "Porque todavía soy un diente de leche" (2000: 45).

Estos rasgos se encuentran enmarcados en un discurso conversacional 
indirecto. El acto de la enunciación hablante - oyente (lector) remite a los actos de hablar como "tutear, decir, consultar" a la muerte, la cual se encuentra tematizada en una breve narración. Este hecho acontece de similar forma en "La muerte está sentada a los pies de mi cama".

Ahora bien, para transitar libremente por el siguiente poema: "Ciudad en llamas" se deberá sortear un retorno del hablante desde ADM hasta Imágenes nucleares (1983), revelando hechos avisados en el discurso fundacional de ERN.

En los siguientes versos: "Entré por alta luz por alto amor / entréme y encontréme padecer..." (2000: 56), pues, se recrea la muerte nuclear anunciada en "Reencarnación de los carniceros" de ERN, el cual se encuentra ubicado en el último lugar de la serie y cerrando el círculo hasta ADM; luego de cumplida la profecía. En el caso del último de la serie del carnaval de las muertes adjudicadas al primer texto de ADM “Adán postrero", el hablante ha cursado la primera etapa, la crónica de las muertes referidas en ERN.

Por su parte, el hablante enunciador se encuentra sumido en la soledad de la espera, avisado por la enunciación del primer discurso (ERN). Aunque éste se desplaza desde la euforia psíquica, sustentada en las pasiones ejercidas por la inconsistencia de la subjetividad del primer discurso hasta el postrer evento de ADM. Esta disforia que, tal vez, obedece a la asunción de la realidad no sólo se encuentra en el otro discurso, además, es evidente en éste.

De igual modo, la intertextualidad autártica permite retomar el primer poema de ERN. Allí aparecen: "Dios, la existencia, las ondas circulares", transportando al hablante en el círculo de la muerte, semantizada ahora por la "mutante" de ADM. Así también, el hablante ha experimentado la cercanía con los demonios que acusa, los cuales volverán más tarde en otras muertes, al parecer radiactivas: "Sentado en un montón de escombros / Espero a la mutante que será mi mujer" (2000: 64).

Aunque aquello cierra un ciclo y da inicio a un nuevo círculo construido por la pronominalización, se implica con ello toda la carga significativa de la espera implícita en la marca verbal "espero". Por ahora, se dirá que el hablante de la enunciación es un conocedor de los dominios de la muerte. Este se muestra confiado y paciente, aunque todavía un diente de leche. Por demás, permite que le arranquen una costilla; de lo cual se infiere que ha de ser el Dios del primer discurso el facilitador de la segunda muerte, aquélla señalada como radiactiva. Ahora, en la creación del nuevo discurso, este mismo es quien re-semantiza a la muerte cubriéndola de muertes: "Y se aleja pisando 
cenizas radiactivas" (2000: 64). Del mismo modo, se dirá que la intertextualidad de "Reencarnación de los carniceros" también se aproxima por "Visión de Hiroshima”. Así, cabe señalar que esta última es una muerte colectiva, a diferencia de aquella individual de "El muerto de Nagasaki".

Pues, hasta aquí se han cumplido los dichos del primer discurso: "Y vi que...", dando cuenta de las verdaderas voces enunciativas de la historia, la que se reinicia en el ejercicio de la soledad de "Adán postrero". Como ya se anunciara: "Sentado en un montón de escombros / espero a la mutante que será mi mujer" (2000: 64).

Este tema introduce aquella enseñanza del exilio que conectará al poeta con la realidad de otro espacio construido por la depredación de la muerte radiactiva en donde se acercará al exilio: "el viento dispersa árboles calcinados" (2000: 64). Se debe aclarar que en el exilio la solidaridad es el ejercicio afortunado de compartir. No obstante, en el verso de Hahn se hace por una vía poco afortunada. Puesto que las marcas léxicas, gramaticales enunciadas, están cargadas por el infortunio, incluso, implicando la ausencia del reconocimiento del yo, o sea de la subjetividad. Se infiere que éstas serán las marcas del exilio de sí mismo, motivado por la experiencia, aunque conducentes a la solidaridad; pues, si bien muy distinta a otras, ésta será aquella que reconoce sus carencias y que se descubre en las muertes colectivas. Por lo tanto, la solidaridad no será la simple manera de estar con otros, será el sentir a los otros. Por analogía, éste será un ejercicio empático al ponerse en el lugar de los demás y al representarse en las muertes de esos otros.

Recapitulando, los textos estudiados en la intertextualidad y sus variantes se expresan en rasgos verbales, pronominales, adverbiales. Además, los marcadores discursivos del segundo discurso serán re-semantizados en nuevas relaciones dialógicas confrontadas con el referente de la enunciación, todo lo cual permite una nueva lectura uniforme para acercarse explícitamente a la representación de la subjetividad del poeta.

\section{CONCLUSIONES}

En consideración a Esta rosa negra como el texto fundacional de la escritura de Óscar Hahn, se dirá que el hablante se representa a través de marcas gramaticalizadas en pronombres y verbos que revelan incertidumbre, duda como, además, por medio de la figura metafórica que recrea la vida conectada a la idea del exilio en connotación del abandono existencial, ya que el 
exilio histórico aún no se ha concretado. De manera congruente, se infiere de lo anterior que las marcas gramaticalizadas revelan un discurso del desarraigo y la ausencia de la subjetividad asumida. Asimismo, conectando estas lecturas que confirman la lucidez del autor ante el conflicto personal y social de la historia pre-postgolpe militar, se postula que la soledad es un concepto presente en el primer discurso fundacional, denotando con ello la escritura de la soledad. Así pues, este desarraigo personal se conectará al inminente problema social posterior. En suma, los elementos connotativos del desarraigo y la soledad serán dos imágenes subyacentes a las marcas ya referidas, las que denuncian un carácter explícito de querer distanciarse de aquello que daña la convivencia con la existencia y la vitalidad del ser humano, en fin, la del poeta enunciador. Así, consciente o no, sus textos reflejan una vida difusa y sumida en el desamparo, conectándose con aquellas muertes presentes en su inminente soledad.

En cuanto a Arte de morir, el acto de la enunciación (hablante - oyente 'lector') se conecta con el referente de la muerte, aunque explícitamente en la soledad de las muertes abordadas por el hablante a través del tiempo, ya de manera vital en la enseñanza del exilio que se inicia con el ejercicio de la soledad. No obstante, se puede concluir que la convivencia con otras personas en otra cultura y la de asumir la muerte individual y colectiva de la realidad histórica en Chile, conmueven al hablante enunciador de estos dos discursos. Entonces, la falta de subjetivación en los enunciados de sus poemas se demuestran como la evidencia de una estrategia de sobrevivencia.

Por demás, se infiere que la reiteración y la re-contextualización de muchos poemas en diversas etapas de la vida personal de Óscar Hahn, obedece a la reconstrucción de un mismo discurso, desarrollado con el fin de explicitar el proceso de la construcción de la subjetividad enunciativa. De acuerdo a ello, se dirá que la identidad del hombre se crea a partir de la experiencia para dominar su ser, según lo expuesto por Ortega y Gasset (1965: 157); las instancias que conducen al descubrimiento de la 'subjetividad', con el fin de dominar la conciencia, la interioridad del pensamiento y, su ser. Esto último se constituirá como la clave para reconocerse como un hombre en el curso de la modernidad. A modo de afirmación conclusiva: la soledad, el desarraigo, el abandono subyacentes en los rasgos enunciativos obedecen a la inminente necesidad de tomar distancia de la realidad que agobia al poeta, así, consciente o no, sus textos son el reflejo difuso de su imagen personal en un período de la historia social chilena, vivida para muchos entre las sombras y la luz. 


\section{REFERENCIAS}

Álvarez, Alexandra. (2005). Atenuantes y sus funciones corteses. En Diana Bravo (coord.), Estudios de la (des)cortesía en español (pp. 119-144). Buenos Aires: Dunken.

Austin, John. (1962). Cómo hacer cosas con palabras. Barcelona: Paidós.

Benveniste, E. (1997). Problemas de lingüistica general II. México: Siglo XXI editores.

Bianchi, Soledad. (1995). La memoria: Modelo para armar. Santiago: Ediciones de la Dirección de Bibliotecas, Archivos y Museos.

Campos, Javier. (1987). La joven poesía chilena en el periodo 1961 - 1973. (G. Millán, W. Rojas, O. Hahn). Concepción-Minneapolis: LAR-Institute for the Study of Ideologies and Literature.

Cepeda, Gladys. (2005). Atenuantes y sus funciones corteses. En Diana Bravo (coord.), Estudios de la (des)cortesía en español (pp. 163-187). Buenos Aires: Dunken.

Charaudeau, Patrick. (1992). Grammaire du sens et de l'expression. Paris: Hachette Education.

. (2001). La competencia social de comunicación a las competencias discursivas. Revista Latinoamericana de Estudios del Discurso (ALED), $1,7-22$.

Dallenbach, Lucien. (1976). Intertexte et autotexte. Poètique, 27, 282-296.

Di Tullio. Ángela. (2005). Manual de gramática del español. Buenos Aires: La Isla de la Luna.

Donoso Pareja, Miguel. (1992). Lenguaje y producción de la literatura: identidad. En Congreso Internacional de Escritores. Ponencias (pp. 153159). Santiago: Sociedad de Escritores de Chile (SECH).

Ducrot, Oswald. (1986). El decir y lo dicho. Polifonia de la enunciación. Madrid: Paidós Comunicación.

Ducrot, Oswald y Tzvetan Todorov. (1972). Diccionario enciclopédico de las ciencias del lenguaje. Buenos Aires: Siglo XXI Editores.

Eco, Umberto. (1995). Tratado de Semiótica general. Barcelona: Lumen.

Flores, Jorge. (1991). Metodología del conocimiento. Guatemala: Instituto de Investigaciones y Mejoramiento Educativo IIME.

Galindo, Óscar. (2002). Autoritarismo, enajenación y locura en la poesía chilena de fines del siglo XX. Zurita, Maquieira, Cuevas. América Latina Hoy, 30, 97-118.

Grau, María. (2005). La modalización: adecuación del texto a los parámetros de la situación comunicativa. En Montserrat Vilà i Santasusana 
(coord.), El discurso oral formal. Contenidos de aprendizaje y Secuencias didácticas (pp. 77-88). Barcelona: Graó.

Hahn, Óscar. (1982). Sobre la creación de los precursores y otras fantasmagorías. Atenea, 446, 129-135. . (1983). Imágenes nucleares. Santiago: América del Sur. . (1996) [1961]. Esta rosa negra. Santiago: Editorial Platero. (2000) [1977]. Arte de morir. Santiago: LOM.

Haverkate, Henk. (1994). Cortesía verbal. Estudio pragmalingüistico. Madrid: Gredos.

Maingueneau, Dominique. (1976). Introducción a los métodos de análisis del discurso. Problemas y perspectivas. Argentina: Hachette.

. (2004). ¿Situación de enunciación o situación de comunicación? Traducido por Laura Miñones (UBA). [on line] Disponible en http://es.scribd.com/doc/98809453/Maingueneau-D-2004-Situacionde-enunciacion-o-situacion-de-comunicacion.

Martínez, María Cristina. (1997a). Discurso, proceso y significación. Estudios de análisis del discurso. Cali: Editorial Universidad del Valle.

(1997b). Los procesos de la lectura y la escritura. Cali: Editorial Universidad del Valle.

(2005). La construcción del proceso argumentativo en el discurso. Cali: Universidad del Valle.

Morín, Edgar. (1994). La noción de Sujeto. En Dora Fried Schnitman (ed.), Nuevos paradigmas, cultura y subjetividad (pp. 67-90). Buenos Aires: Paidós.

Ortega y Gasset, José. (1965). Qué es filosofía. Madrid: El Arquero, Revista de Occidente.

Roa, Alejo. (1989). Gramática castellana. Santiago: Editorial Salesiana.

Searle, John. (2001). Actos de habla. Madrid: Cátedra.

Vodicka, Félix y Oldrich Belic. (1972). El mundo de las letras. Santiago: Editorial Universitaria. 